\title{
Older age groups and country-specific case fatality rates of COVID-19 in Europe, USA and Canada
}

\author{
Christian Hoffmann ${ }^{1,2}$ (D) Eva Wolf ${ }^{3}$ (D)
}

Received: 12 August 2020 / Accepted: 5 October 2020 / Published online: 24 October 2020

(c) The Author(s) 2020

\begin{abstract}
Purpose To evaluate the association between the percentages of older age groups among confirmed SARS-CoV-2 infections and the country-specific case fatality rate (CFR).

Methods This ecological study analyzed data from the 20 most severely affected European countries, USA and Canada, in which national health authorities provided data on age distribution and gender among confirmed SARS-CoV-2 cases and deaths.

Results The proportion of individuals older than 70 years among confirmed SARS-CoV-2 cases differed markedly between the countries, ranging from 4.9 to $40.4 \%$. There was a strong linear association between the proportion of individuals older than 75 years and the country-specific CFRs $\left(R^{2}=0.803\right.$ for all countries, $R^{2}=0.961$ after exclusion of three countries with incongruent data). Each 5\% point increase of this older age group among confirmed SARS-CoV-2 cases was associated with an increase in CFR of $2.5 \%$ points (95\% CI 1.9-3.1).

Conclusion Data from 20 European countries and the USA and Canada showed that the variance of crude CFR of COVID19 is predominantly (80-96\%) determined by the proportion of older individuals who are diagnosed with SARS-CoV-2. The age distribution of SARS-CoV-2 infections is still far from being homogeneous. Detailed demographic data have to be taken into account in all the analyses on COVID-19-associated mortality. We urgently call for standardized data collection by national health authorities.
\end{abstract}

Keywords SARS-CoV-2 $\cdot$ COVID-19 $\cdot$ Case fatality rate $\cdot$ Age distribution

\section{Introduction}

In the current pandemic, the country-specific crude case fatality rates (CFRs), the percentage of COVID-19-associated deaths among confirmed SARS-CoV-2 infections, have been the subject of much speculation. Although it became quickly clear that older age is a major risk factor for mortality $[1,2]$ and that in particular an age of over 70 years is

Electronic supplementary material The online version of this article (https://doi.org/10.1007/s15010-020-01538-w) contains supplementary material, which is available to authorized users.

Christian Hoffmann

hoffmann@ich-hamburg.de

1 ICH Study Center, 20146 Hamburg, Germany

2 Department of Medicine II, University of Schleswig-Holstein, Campus Kiel, Kiel, Germany

3 MUC Research GmbH, 80335 Munich, Germany associated with a markedly higher CFR [3, 4], many other factors contributing to regional differences throughout the world have been discussed in recent months.

These factors include not only differences in the overall age structure of the general population of a country and coresidence patterns [5], but also comorbidity burden, obesity prevalence and smoking habits [6] as well as societal and social psychological factors [7]. Others include heterogeneity in testing and reporting approaches [8], variations in health care system capacities and health care [9] and even political regime [10]. Different virus strains $[11,12]$ or even environmental factors such as air pollution [13-15] have also been discussed, as well as potential differences in genetic variability [16-19] or "trained immunity" induced by certain live vaccines such as bacillus Calmette-Guérin [19-21].

Most articles have considered that older age plays a vital role in influencing severe disease and negative clinical outcomes. However, to clarify the association of older age groups diagnosed with SARS-CoV-2 infection with the 
country-specific CFR, we have collected available age- and gender-specific data provided from national health authority websites of the 20 most severely affected European countries and of USA/Canada.

\section{Methods}

For Europe, we evaluated the 20 most severely affected larger countries, as defined by numbers per million inhabitants and with at least 1000 confirmed infections. Country-specific confirmed case and death numbers to estimate the countryspecific CFR, as well as all available data on age distribution of confirmed cases and deaths were extracted from national health authority websites of European countries and Canada by July 6, 2020 (see supplement). Age-specific data were available for Belgium, Denmark, Germany, Iceland, Ireland, Italy, Moldova, Netherlands, Portugal, Spain, Sweden, Switzerland, and the United Kingdom. For France, only a limited number of cases reported to center laboratories were available. Six countries did not report age-specific data (Armenia, Luxemburg, North Macedonia, Turkey, Serbia and Bosnia Herzegovina) and were replaced by the countries ranking next in order of numbers, namely Austria, Norway, Romania, Estonia, Finland and the Czech Republic. For the USA, we used a detailed report on 1,320,488 laboratory-confirmed COVID-19 cases individually reported to Centers of Disease Control [22].

The numbers of confirmed SARS-CoV-2 cases and deaths were collected as well as the corresponding reported age strata and gender distribution. In countries where only age groups of 65-74 years were available for confirmed cases (see Supplement), we assigned 50\% to the group over 70 years. We also performed sensitivity analyses by assigning not only $50 \%$ but also $33 \%$ and $67 \%$ of cases to the younger age groups in countries using different age strata for reporting confirmed SARS-CoV-2 cases (resulting in overlapping strata). For the age group of over 70 years, the percentage of this age group among deaths was assessed. For the association between the country-specific percentage of age group over 70 and age group over 75 years among confirmed infections and the country-specific CFRs, linear regression analyses were performed. Countries were weighed according to their total numbers of COVID-19-associated deaths.

In countries in which age strata and gender distributions were available for both cases and deaths, we estimated the age-stratified CFRs, dividing the absolute death numbers by the cases in a given age group, separately for women and men. Given the heterogeneous reporting in most countries, only three age groups were used, namely $<60$ years, $60-79$ years and $>80$ years. The overall age-specific case fatality risk ratios across countries for men compared to woman (including 95\% confidence intervals (CI) and $I^{2}$ as measure of consistency/heterogeneity) were estimated using a random effects model applying the method of DerSimonian and Laird. Statistical analyses were performed using Stata/SE 15.1, StataCorp LLC, USA.

\section{Results}

At the time of data-cut (July 6, 2020), a total of about 3.36 million confirmed SARS-CoV-2 cases and 283,792 associated deaths had been documented for the 22 countries, yielding an overall CFR of $7.28 \%$. As shown in Table 1, the country-specific CFR showed a broad spectrum, ranging from 0.6 (Iceland) to $18.1 \%$ (France). Six countries reported a CFR of $>10 \%$, namely Belgium, Spain, Italy, Netherlands, France and the United Kingdom. Countries with a relatively low CFR of $<4 \%$ were Iceland, Estonia, Moldova, Austria, Norway, Portugal and the Czech Republic.

The data extent and quality in reporting age- and gender-specific data varied considerably between the countries (supplement). Only a few countries reported different age groups for both cases and deaths stratified by gender. In total, roughly 2.63 million confirmed SARS-CoV-2 cases with available age data could be included in the analysis (82.6\% of all reported infections in these countries).

Except for Austria, male patients accounted for less than half of the confirmed diagnoses, with the lowest rates of male patients in France, Belgium and the Netherlands. In contrast, male patients accounted for more than 50\% among SARS-CoV-2-associated deaths in most countries. Except for Norway and Finland, in all the countries, male patients had a higher crude mortality risk with a risk ratio varying between 1.08 (Canada) and 2.01 (Netherlands).

The proportions of patients older than 70 years among confirmed SARS-CoV-2 infections differed markedly between countries, ranging from 4.9 (Iceland) to $40.4 \%$ (United Kingdom).

As shown in Table 1, the age group older than 70 years accounted for 79-89\% of COVID-19-associated deaths in 16 of 20 countries with available data (Estonia and France did not report these rates). In the four countries with lower rates, the proportion of older age groups among deaths increased markedly to $77.1 \%$ (Moldova), $78.4 \%$ (Romania), $87.5 \%$ (USA) and $90 \%$ (Iceland) when the age group 60-70 years was included.

There was a strong association between the proportion of older patients and the country-specific CFRs in our linear regression model (Fig. 1). For the proportion of patients older than 75 years (70 years), $R^{2}$ values were $0.803(0.766)$, explaining $80.3 \%$ (76.6\%) of the variance in the countryspecific CFR rates. Each 5\% point increase of individuals above 75 years among SARS-CoV-2 cases was associated 


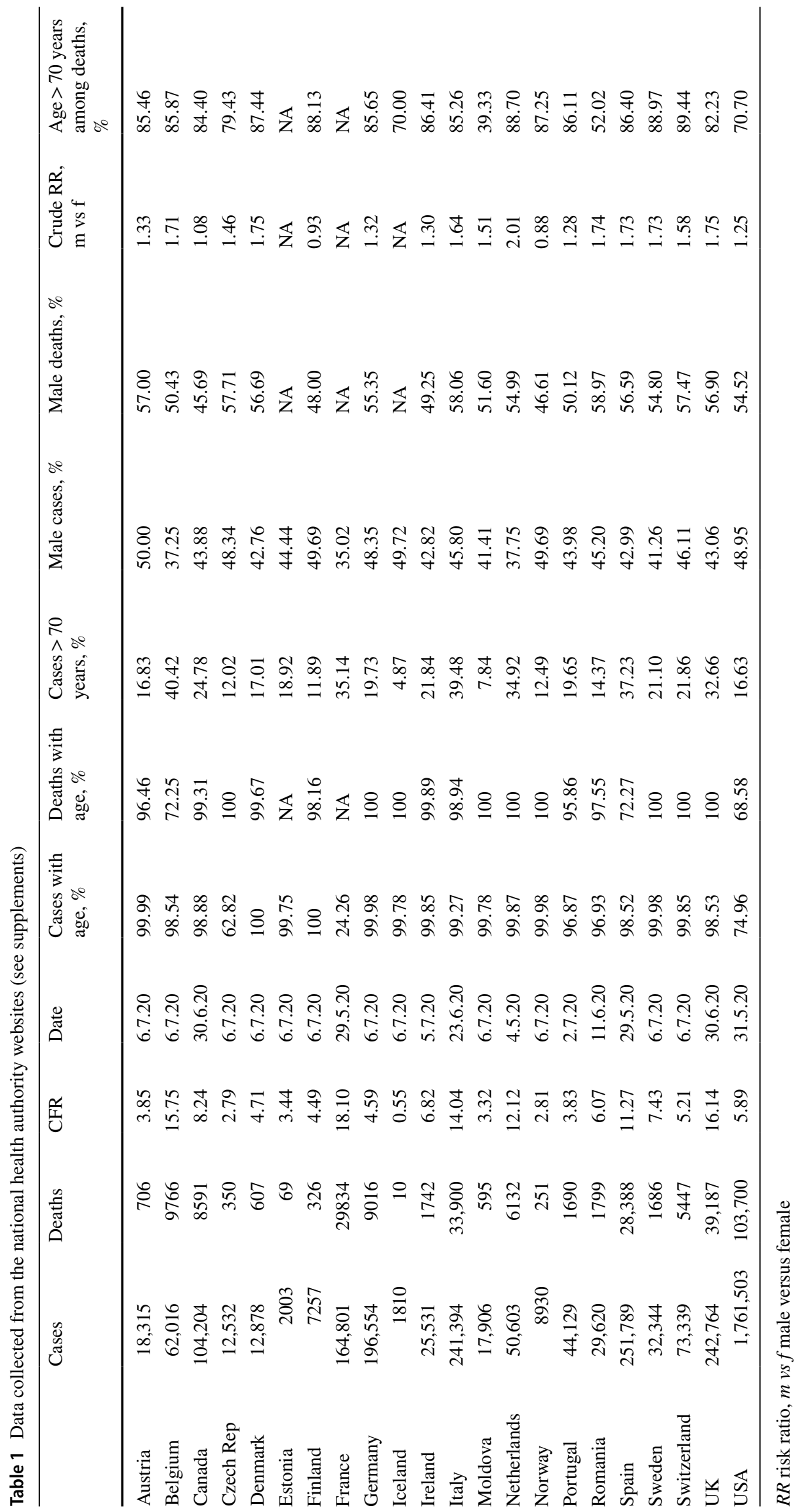


Fig. 1 Association between case fatality rate (CFR) and the proportion of persons over 75 years of age among all confirmed SARS-CoV-2 cases $\left(R^{2}=0.8034, p<0.0001\right)$. The circle sizes reflect the countryspecific numbers of COVID19-associated deaths per million habitants; the linear fit prediction plot with a $95 \%$ confidence interval was estimated by weighted linear regression (weight $=$ total number of COVID-19-associated deaths)

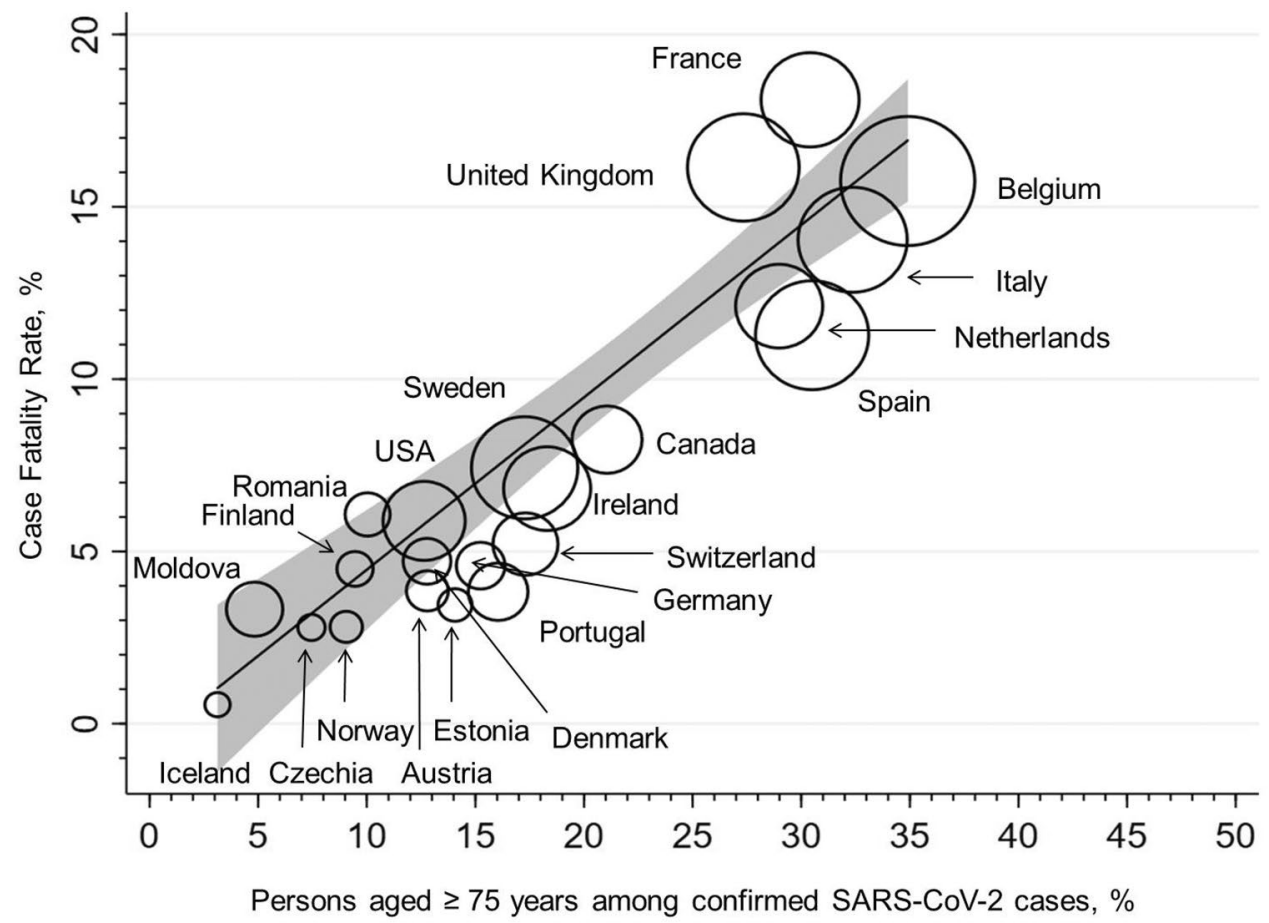

with an increase in overall CFR of $2.5 \%$ points $(95 \%$ CI $1.9-3.1 \%$ points). Similar results were seen when adjusting for gender or when an unweighted linear regression was performed (data not shown). Results remained also stable when in countries using different age strata for reporting confirmed SARS-CoV-2 cases (resulting in overlapping strata), $33 \%$ or $67 \%$ (instead of $50 \%$ as in the main analysis) of cases were assigned to the younger age group.

When France (which had a very low rate of infections with known age) and Spain (for which numbers and methodology were corrected several times, implying uncertainty in numbers) were excluded, $R^{2}$ values were 0.868 and 0.856 for patients older than 75 and 70 years of age, respectively. If UK is also excluded (as around $66 \%$ of the UK data derived from mostly hospitalized patients, probably overestimating CFR), $R^{2}$ values were 0.961 and 0.960 , respectively.

We have also applied our model to other countries outside Europe that have provided detailed data on age distribution among confirmed SARS-CoV-2 cases such as Australia, Singapore, Japan, China, Republic of Korea or Brazil, yielding very similar results (data not shown).

In Fig. 2, the age- and gender-specific CFR are shown for the eight countries for which these data were available. The UK had the highest CFR in all three age groups, followed by Italy and Canada. Compared to women, CFRs of men were higher in almost all countries across age groups. The estimated overall risk ratio (i.e., relative risk; RR) for men compared to women was highest in younger age groups. In individuals aged $<60$ years, 60-79 years and $>80$ years, the RR for men was 2.65 (95\% CI $\left.2.18-3.21 ; I^{2}=82 \%\right)$, $1.73\left(1.55-1.93 ; I^{2}=93 \%\right)$ and $1.50\left(1.36-1.65 ; I^{2}=97 \%\right)$, respectively. Of note, country-specific CFRs were all significantly higher for men in the three age groups apart from Moldova and Norway in the age group $>80$ years (harboring both a broad confidence interval including a RR of 1).

\section{Discussion}

The striking differences in country-specific case fatality rates observed throughout the world have prompted a huge debate and speculations about the reasons. A myriad of heterogeneous factors contributing to country-specific differences has been evaluated, suggested and proposed during recent months, including genetic, viral, medical, socioeconomic and environmental issues [5-21].

The present analysis of 20 European severely affected countries, USA and Canada strongly indicates that the crude CFR of COVID-19 is predominantly determined by the proportion of patients aged older than 75 years of all individuals diagnosed with SARS-CoV-2 infection. Our simple regression model explained more than $80 \%$ of the variance between the countries. Of note, our intention was neither to apply complex mathematical models nor to question the role of other factors contributing to variations in mortality. However, when these factors are discussed and evaluated, detailed information on age distribution among the confirmed SARS-CoV-2 cases have to be taken into account. This is all the more important when countries report relatively low CFRs. In the case of Germany, Russia or India, 


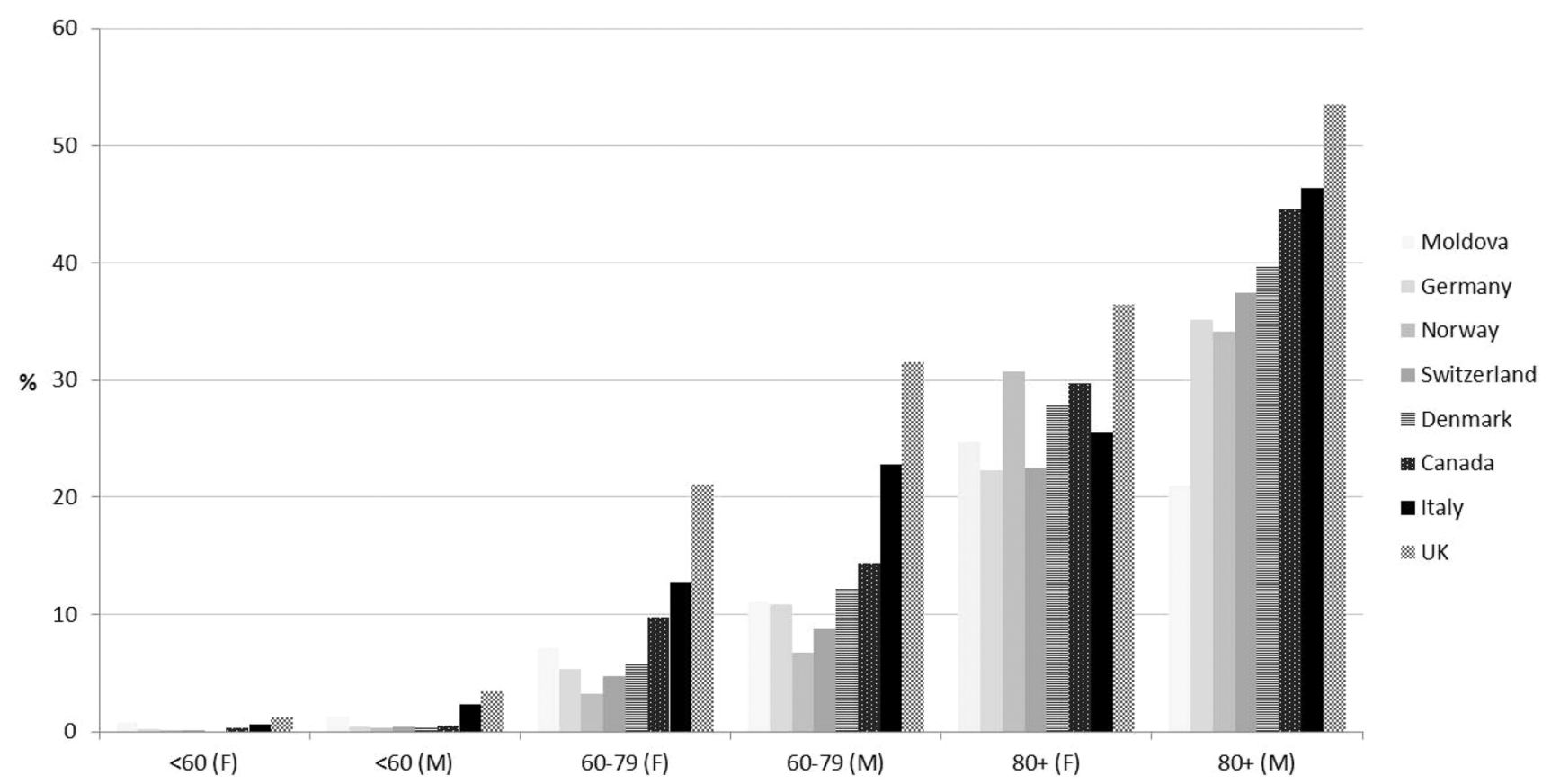

Fig. 2 Age- and gender-specific CFR (percentage) for the eight countries in which these data were available. The relative risk (or risk ratio; i.e., RR) for men compared to women was highest in younger age groups. In individuals aged $<60$ years, 60-79 years

for example, many explanations have been put forward for the relatively low mortality rates in these countries and have been subject to speculations in the media [8, 23, 24]. Reporting of the age structure of the infected populations is needed before definitive conclusions can be made.

Our data confirm and extend the findings of a recently published early analysis of data reported until April 19, 2020 in which age-standardization of CRFs reduced their variation (standard deviation) by $66 \%$ across nine countries [25].

Our data also show that, even in a phase of declining infection numbers (in Europe and Canada), there are still dramatic differences in the proportion of older age groups among confirmed SARS-CoV-2 cases, ranging from 4.9 to $40.4 \%$ in European countries. Although we did not have information on testing policies or on different reporting systems of cases and deaths, the present data indicate marked differences between the age distribution of the SARS-CoV-2 epidemic. In many European countries, the distribution of SARS-CoV-2 infections in the general population is still far from homogeneous. We speculate that the marked variation of CFR across countries could diminish over time, especially if less affected countries fail to protect their older age groups. However, the variation of the CFR in specific age groups as shown in Fig. 2 may also decrease with the availability of larger, well-conducted epidemiological studies evaluating the true seroprevalence in countries. We would expect that this would at least diminish the potential bias and $>80$ years, the estimated overall RR for men versus women was 2.65 (95\% CI 2.18-3.21), 1.73 (1.55-1.93) and 1.50 (1.36-1.65), respectively

of regional testing policies, capacities and restrictions for confirmatory testing.

In the countries with available data on gender and age groups in both cases and deaths, we found marked differences between countries and between women and men. In almost all countries, the CFR for men was markedly higher in all age groups, especially in younger age groups. The particularly high rates in the UK may be in part explained by the two-phase official testing programme. Due to limited testing capacity, during the first phase, the strategy was to perform confirmatory SARS-CoV-2 testing only in hospitals and for those with a medical need. Around $66 \%$ of the confirmed cases in the UK were derived from the first phase, probably overestimating CFR there.

There is no doubt that our study has several limitations. We could not analyse the age groups more in detail and did not stratify age groups for gender as not many countries reported gender-specific age distribution in both cases and deaths. For some larger countries such as Turkey or France, data on ages were completely missing or incomplete. Many other factors were neglected, such as testing policies and other important health care issues.

However, our simple analysis of 20 European countries and USA and Canada strongly indicates that the crude CFR of COVID-19 appears to be predominantly determined by the proportion of patients older than 70-75 years of age who are diagnosed with SARS-CoV-2. We urgently call 
for standardized data collection by national health authorities. The numbers of confirmed cases and deaths should be precisely stratified by gender and age groups, preferably grouped at 5-year intervals for all subgroups.

Author contributions $\mathrm{CH}$ conceived the original idea of this research. Both the authors, EW and $\mathrm{CH}$, developed the operationalized research question and the statistical analysis plan. EW performed the statistical analyses. $\mathrm{CH}$ took the lead in and EW contributed to the writing of the manuscript.

Funding Open Access funding enabled and organized by Projekt DEAL. There was no funding.

Data availability See supplements.

Code availability Statistical analyses were performed using Stata/SE 15.1, StataCorp LLC, USA.

\section{Compliance with ethical standards}

Conflict of interest The authors C.H. and E.W. certify that they had no conflict of interest that could affect their objectivity. The authors declare no support from any organization for the submitted work and no financial relationships with any organization that might have an interest in the submitted work in the previous 3 years. There are no other relationships or activities that could appear to have influenced the submitted work.

Open Access This article is licensed under a Creative Commons Attribution 4.0 International License, which permits use, sharing, adaptation, distribution and reproduction in any medium or format, as long as you give appropriate credit to the original author(s) and the source, provide a link to the Creative Commons licence, and indicate if changes were made. The images or other third party material in this article are included in the article's Creative Commons licence, unless indicated otherwise in a credit line to the material. If material is not included in the article's Creative Commons licence and your intended use is not permitted by statutory regulation or exceeds the permitted use, you will need to obtain permission directly from the copyright holder. To view a copy of this licence, visit http://creativecommons.org/licenses/by/4.0/.

\section{References}

1. Huang C, Wang Y, Li X, Ren L, Zhao J, Hu Y, et al. Clinical features of patients infected with 2019 novel coronavirus in Wuhan, China. Lancet. 2020;395:497-506.

2. Guan WJ, Ni ZY, Hu Y, Liang WH, Ou CQ, He JX, et al. Clinical characteristics of coronavirus disease 2019 in China. N Engl J Med. 2020;382:1708-20.

3. Livingston E, Bucher K. Coronavirus Disease 2019 (COVID-19) in Italy. JAMA. 2020;323:1335.

4. Wu JT, Leung K, Bushman M. Estimating clinical severity of COVID-19 from the transmission dynamics in Wuhan, China. Nat Med. 2020;26:506-10.

5. Esteve A, Permanyer I, Boertien D, Vaupel JW. National age and coresidence patterns shape COVID-19 vulnerability. Proc Natl Acad Sci USA. 2020;23:202008764.

6. Guan WJ, Liang WH, Zhao Y, Liang HR, Chen ZS, Li YM, et al. Comorbidity and its impact on 1590 patients with COVID-19 in China: a nationwide analysis. Eur Respir J. 2020;55:2000547.
7. Oksanen A, Kaakinen M, Latikka R, Savolainen I, Savela N, Koivula A. Regulation and trust: 3-month follow-up study on COVID-19 mortality in 25 european countries. JMIR Public Health Surveill. 2020;6:e19218.

8. Stafford N. Covid-19: Why Germany's case fatality rate seems so low. BMJ. 2020;7:m1395.

9. Dongarwar D, Salihu HM. COVID-19 pandemic: marked global disparities in fatalities according to geographic location and universal health care. Int J MCH AIDS. 2020;9:213-6.

10. Sorci G, Faivre B, Morand S. Why does COVID-19 case fatality rate vary among countries? https://www.medrxiv.org/conte nt/10.1101/2020.04.17.20069393v1.full.pdf

11. MacLean O, Orton RJ, Singer JB, et al. No evidence for distinct types in the evolution of SARS-CoV-2. Virus Evol. 2020. https:// doi.org/10.1093/ve/veaa034.

12. Tang Y, Wu C, Li X, Song Y, Yao X, Wu X, et al. On the origin and continuing evolution of SARS-CoV-2. Natl Sci Rev. 2020;7:101223. https://doi.org/10.1093/nsr/nwaa036.

13. Amoo EO, Adekeye O, Olawole-Isaac A, Fasina F, Adekola PO, Samuel GW, et al. Nigeria and Italy divergences in coronavirus experience: impact of population density. Sci World J. 2020;21:8923036.

14. Ogen Y. Assessing nitrogen dioxide (NO2) levels as a contributing factor to coronavirus (COVID-19) fatality. Sci Total Environ. 2020;15:138605.

15. Yao Y, Pan J, Wang W, Liu Z, Kan H, Qiu Y, Meng X, Wang W. Association of particulate matter pollution and case fatality rate of COVID-19 in 49 Chinese cities. Sci Total Environ. 2020;20:140396.

16. Li Q, Cao Z, Rahman P. Genetic variability of human angiotensinconverting enzyme 2 (hACE2) among various ethnic populations. Mol Genet Genomic Med. 2020;18:e1344.

17. Asselta R, Paraboschi EM, Mantovani A, Duga S. ACE2 and TMPRSS2 variants and expression as candidates to sex and country differences in COVID-19 severity in Italy. Aging (Albany NY). 2020;12:10087-98.

18. Ghafouri-Fard S, Noroozi R, Vafaee R, et al. Effects of host genetic variations on response to, susceptibility and severity of respiratory infections. Biomed Pharmacother. 2020;128:110296.

19. Chakrabarti SS, Kaur U, Banerjee A, et al. COVID-19 in India: Are biological and environmental factors helping to stem the incidence and severity? Aging Dis. 2020;11:480-8.

20. Netea MG, Giamarellos-Bourboulis EJ, Domínguez-Andrés J, Curtis N, van Crevel R, van de Veerdonk FL, Bonten M. Trained immunity: a tool for reducing susceptibility to and the severity of SARS-CoV-2 infection. Cell. 2020;181:969-77.

21. Escobar LE, Molina-Cruz A, Barillas-Mury C. BCG vaccine protection from severe coronavirus disease 2019 (COVID-19). Proc Natl Acad Sci USA. 2020;9:202008410.

22. Stokes EK, Zambrano LD, Anderson KN, Marder EP, Raz KM, Felix SE, et al. Coronavirus disease 2019 case surveillance-United States, January 22-May 30, 2020. MMWR Morb Mortal Wkly Rep. 2020;69:759-65.

23. Lancet T. Salient lessons from Russia's COVID-19 outbreak. The Lancet. 2020;395:1739.

24. Pulla P. The epidemic is growing very rapidly': Indian government adviser fears coronavirus crisis will worsen. Nature. 2020;583:180. https://media.nature.com/original/magazine-assets/d41586-02001865-w/d41586-020-01865-w.pdf

25. Sudharsan N, Didzun O, Bärnighausen T, Geldsetzer P. The contribution of the age distribution of cases to COVID-19 case fatality across countries. A 9-Country demographic study. Ann Int Med. 2020. https://doi.org/10.7326/M20-2973. 